\title{
VIVÊNCIAS DIFERENCIADAS ENTRE TRESS GERAÇÕES DE JAPONESES EM SÃO PAULO
}

\author{
Zeila de Brito Fabri Demartini*
}

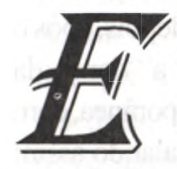
stas reflexões estão pautadas em dois estudos complementares realizados junto a famílias de imigrantes japoneses ${ }^{1}$. No primeiro abordamos famílias de origem japonesa que vieram para as cidades de Campinas e São Paulo durante as primeiras cinco décadas desse século (19081950) (Demartini, 1997a). Focalizamos nossa atenção especialmente em temas relacionados à educação, aos hábitos culturais e atividades de lazer. $\mathrm{Na}$ segunda etapa aprofundamos nosso conhecimento sobre as questões estudadas anteriormente, bem como incluímos novas indagações e elementos de análise, que foram surgindo na medida que avançamos com essa caracterização mais ampla do grupo estudado. Portanto, os temas relacionados com a mobilidade sócio-espacial dessas famílias, os projetos individuais e coletivos de ascensão sócio-econômica, o processo de escolarização das gerações mais jovens e a vivência cultural nas últimas décadas foram examinadas sob um novo prisma, a partir de uma análise de gerações que compõem cada família e as diferenças sociais, econômicas e sobretudo culturais ao longo deste século (Demartini, 1997b).

\section{PESQUISAS COM DIFERENTES GERAÇÕES E SUAS IMPLICAÇÕES METODOLÓGICAS}

Falar de gerações sucessivas não significa apenas fazer referência ao fator biológico, onde uma por ser continuidade da outra, caminha para a evolução da espécie. No plano social consideram-se os conflitos pessoais e familiares, as influências do meio (família, trabalho, escola, etc.), os projetos de vida, o convívio cotidiano, dentre outros fatores. Notamos então, que os vários elementos quando conjugados levantam questões relativas a um processo histórico que considera matrizes culturais tanto residuais como as constantes relações do dia a dia. Uma análise comparativa de gerações torna-se relevante, portanto, pois através dela pode-se constatar a dinâmica social e histórica que age de maneira dialética na medida em que estão presentes diversos paradigmas que ora são abandonados, ora fortalecidos, mas na maioria das vezes reinterpretados de acordo com as necessidades e perspectivas individuais de cada membro familiar.

Assim, falar em geração não implica simplesmente em fazer uma referência biológica aos indivíduos. A idéia de geração, durante muito tempo considerada suspeita pelos historiadores, hoje é compreendida como portadora de vários significados tendo cada um sua especificidade. Se falássemos, por exemplo, em geração literária ou partidária certamente os elementos aos quais iriamos recorrer para situá-las seriam bem diferenciados entre si, do mesmo modo se o interesse fosse geração familiar ou científica. Este termo especifica temas e períodos históricos cujo critério de seleção e análise são dados pelo pesquisador. O recorte que se faz determina enfoques e direciona tanto o olhar de quem pesquisa, como do entrevistado e do leitor (Sirinelli, 1996; U. Gehring e P. Gehring, 1991). Nosso trabalho ao abordar famílias japonesas manteve-se nesses termos, sobre alguns planos da discussão geracional e procurou interpretar as diferentes versões vividas por seus membros. Não nos referimos exatamente a uma tra- jetória cronológica, o que se pretendeu foi ampliar o campo da percepção para os contínuos restabelecimentos de relações e conceitos que alimentam os processos de convivência tanto na sociedade mais ampla como dentro do universo familiar. (Delcroix, 1995)

$\mathrm{Na}$ primeira pesquisa, discutimos a migração de famílias japonesas para São Paulo entre o período de 1908 (data da chegada do primeiro navio japonês ao Brasil) até 1950 , a qual denominamos de $1^{\text {a }}$ geração - os Isseis. (Período da $1^{\text {a }}$ Imigração). Na segunda pesquisa discutimos o período compreendido do pós-guerra até os dias de hoje, na qual foram analisados (segundo nossas denominações) a $2^{\mathrm{a}}$ geração (os Nisseis) e seus descendentes, a $3^{\mathrm{a}}$ geração (os Sanseis).

Os estudos com famílias de imigrantes japoneses desenvolveram-se adotando abordagens diferenciadas: trabalhou-se com famílias vivendo em espaços considerados de "colônia" e famílias esparsas em diferentes bairros da cidade de São Paulo. Nos dois casos, foram consideradas famílias que vieram ainda na primeira metade deste século, e famílias que vieram na segunda imigração, no pós-guerra. O processo de pesquisa levou também ao estudo da juventude japonesa, tendo sido entrevistados tanto estudantes universitários que se reúnem em associação de estudantes (ABEUNI-Aliança Beneficente Universitária), como os que convivem mais com os de outras origens.

Para tanto, recorreu-se a fontes diversas: privilegiou-se a realização de entrevistas sob a forma do que denominamos histórias de vida resumidas (Demartini, 1992), em que o relato oral é coletado num processo de interação entrevistadoentrevistador, em que este se coloca numa

10-Travessia / Setembro - Dezembro / 99 
posição de escuta atenta e paciente, de modo a estabelecer a cumplicidade necessária para que o entrevistado se coloque em situação de querer falar. Na segunda fase desta pesquisa, foram de importância fundamental não só o preparo dos pesquisadores sobre as questões referentes ao grupo pesquisado, mas sobretudo os laços já estabelecidos anteriormente com a comunidade nikkei, a presença de pesquisadores do próprio grupo e, no caso das entrevistas com jovens, da mesma faixa etária.

A presença de pesquisadores de mesma faixa etária que os entrevistados, bem como a importante colaboração de uma pesquisadora também descendente de japoneses, contribuiu consideravelmente para que esta pesquisa fosse realizada, possibilitando um diálogo bastante descontraído nas entrevistas, permitindo abordar assuntos pertinentes à juventude com naturalidade, além de enriquecer a pesquisa com convites para outras atividades realizadas pelos jovens, extra-entrevistas, tais como festas e reuniões de trabalho.

Em contrapartida, como os pesquisadores eram na sua maioria não descendentes, muitos momentos de entrevista ficaram prejudicados pela relação de alterida- de emergente, ou seja, os pesquisadores eram "os outros" e por isso nem sempre o encontro pesquisador-pesquisado corria de forma totalmente tranqüila. Alguns assuntos acabaram não sendo abordados mais profundamente em decorrência da própria resistência de alguns entrevistados em revelar aspectos que seriam constrangedores aos entrevistadores; outros, ao contrário, puderam aflorar justamente porque os pesquisadores não eram do próprio grupo.

Além das entrevistas, as fotos e a documentação de posse dos entrevistados e das instituições foram fundamentais durante o processo de entrevista (folhetos, álbuns, livros, etc.). Alguns documentos desta natureza foram objeto de análise posterior na pesquisa, como o álbum sobre os primórdios da Colônia de Itaquera e o livro comemorativo de um grupo de Okinawa, que exigiu tradução para ser trabalhado.

Foram extremamente importantes os censos realizados pela própria comunidade nikkei e que serviam de reflexão comparativa com o trabalho qualitativo que realizávamos através das entrevistas. Através destas pode-se perceber nas trajetórias dos indivíduos e das famílias os processos que têm levado às grandes mudanças evidenciadas pelos números

Para a natureza deste estudo sobre famílias japonesas foi fundamental nesta pesquisa também a observação participante, tanto aquela realizada durante a situação de entrevista, em que visitávamos as famílias e as associações, como aquela que ocorreu durante a participação em aniversários, festas da colônia, bailes e quermesses dos grupos de jovens, excursões etc.

Por tratar-se de estudo em que estamos mais preocupados em reconhecer e explorar a diversidade de representações, a variedade de vivências e estratégias adotadas, do que tentar encontrar padrões uniformes na vivência do grupo de origem japonesa, não se procurou chegar à standartização no sentido apresentado por Bertaux (1980) ao referir-se ao estudo de histórias de vida de grupos específicos da população. Pareceu-nos mais promissor, para este caso, adotar a perspectiva de Franco Ferrarotti (1984) de explorar o social que está contido nas histórias de cada um dos personagens, para a partir daí apreender a trama do social.

Do ponto de vista metodológico, procuramos ao longo de toda pesquisa refletir sobre algumas questões que consideramos importantes, tais como:

1) a realização de histórias de vida com população imigrante japo-

Foto: Reproduzida de álbum de família entrevistada

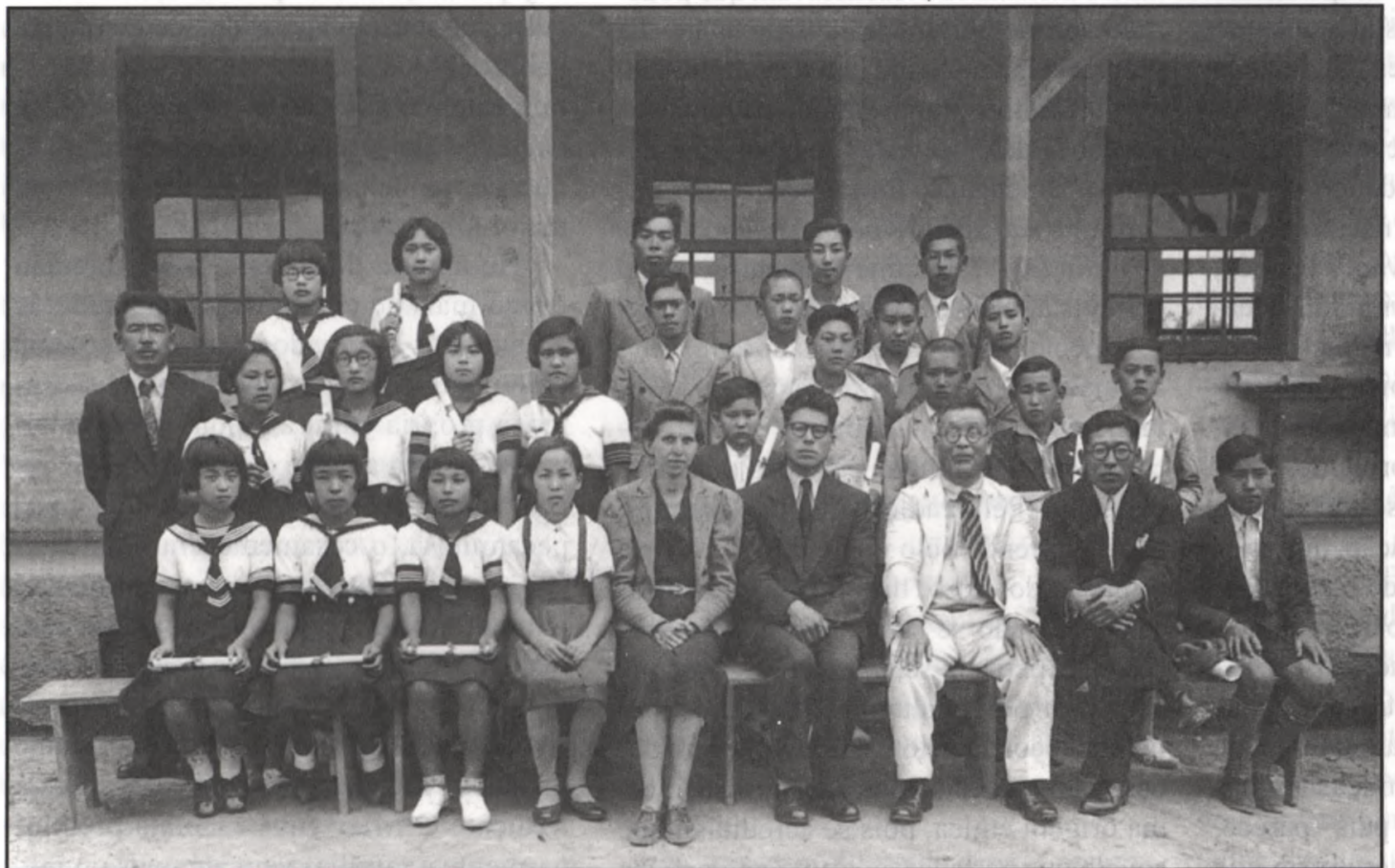

Preparando as novas gerações - Escola japonesa, década de 30, SP(Capital). nesa e com pessoas de diferentes gerações (a situação de entrevista, o modo como os relatos vão se estruturando nas relações dos entrevistados com os diferentes pesquisadores, de idade e grupos étnicos variados, etc.);

2) a especificidade e complementaridade entre as fontes neste estudo das gerações do pós-guerra;

3) a análise do material resultante das entrevistas, da observação e dos documentos escritos e iconográficos.

$\mathrm{Na}$ segunda etapa em que inicialmente planejamos trabalhar com as gerações sucessivas, entrevistando os filhos e netos de 
amos entrevistado na $1^{\text {a }}$ etapa, acreditávamos que em virtude de havermos tido acesso anterior a estas famílias e pelo fato de todos falarem o português e terem nascido e vivido durante todas suas vidas no Brasil, a receptividade seria maior e poder-se-ia realizar as entrevistas com maior facilidade. Mas não foi o que ocorreu: se para os da primeira geração falar livremente era difícil pelas restrições impostas pela língua, pela própria formação e pelos próprios problemas enfrentados, para a $2^{\mathrm{a}}$ geração o problema maior parecia ser o não-reconhecimento de que tinham uma história para contar. Quando íamos procurar alguns dos filhos para a realização de entrevistas, explicitando o interesse pelo estudo das vivências das demais gerações de cada família, muitas vezes escutamos que os pais já haviam dito tudo, que eles não tinham nada para contar, que o importante era a história já contada pelos mais velhos.

Estas respostas, e sua repetição, levaram-nos desde o início do trabalho a refletir sobre alguns aspectos: em primeiro lugar, a pensar em que medida os próprios valores japoneses da hierarquia familiar, o respeito aos mais velhos e aos pais (Vieira, 1973; Maeyama, 1972) não estariam presentes, consciente ou inconscientemente, na recusa em falar sobre suas próprias vidas, na medida em que de alguma maneira poderiam estar contando “outras" histórias, diferentes daquelas já contadas anteriormente; em segundo lugar, a pensar na "desqualificação" da histórią contada pelos filhos, dando estes a entender que suas histórias não eram importantes - elas não carregavam a epopéia vivenciada pelos pais das primeiras décadas, isto é, na aceitação da vivência histórica apenas enquanto "heróica". Interessante que, de modo geral, em todas as famílias entrevistadas anteriormente, a ascensão social concretizou-se justamente através dos filhos, da $2^{a}$ geração, que atingiram níveis mais elevados de escolaridade e bons postos no mercado de trabalho conseguiram o esperado sucesso econômico. Mas suas vidas não trazem geralmente as marcas do deslocamento cultural e das dificuldades econômicas vividas com tanta intensidade pelos pais - parece, pelas colocações, que eles acreditam que fizeram apenas aquilo que se esperava que fizessem, nada mais; não enfrentaram nenhum risco maior, grandes sofrimentos, nem iniciaram grandes mudanças que marcaram os destinos da família e de todo um grupo social, permitindo o sucesso deste grupo.

Com a terceira geração, as dificuldades maiores foram as de encontrar tempo disponível para a realização das entrevistas, pois alguns ainda estudavam e outros trabalhavam. Em alguns casos, foram várias as vezes que os pesquisadores deslocaram-se para bairros muito distantes do centro e não conseguiram realizar as entrevistas, mesmo tendo estas sido marcadas para domingos, dias em que os entrevistados não estariam trabalhando. Nestes casos, a alegação e justificativas para o pedido de adiamento, que ocorreu várias vezes, eram as atividades que deveriam desenvolver junto ao grupo japonês (geralmente atividades esportivas ou ligadas aos grupos de jovens).

Estas experiências foram importantes pois permitiram perceber que se havia, como constatamos na pesquisa anterior, momentos em que a presença de um pesquisador "de fora" do grupo propiciava que se tratasse mais livremente de certos assuntos, por outro lado, os entrevistados, especialmente da segunda geração, em vários momentos evidenciavam que poderiam ser melhor entendidos pelos de sua própria origem. Assim, era mais fácil, sendo do mesmo grupo étnico, enfrentar as situações de entrevistas sem ter que responder à indagação formulada por alguns: "por que são sempre pessoas de fora que nos estudam'? Durante uma entrevista, o entrevistado em certos momentos dirigiase especialmente à pesquisadora nissei $\mathrm{e}$ afirmava: "você me entende, não é?" Códigos do grupo, o "habitus" oriental incorporado, em muitas ocasiões difícil de explicitar. Pela tradição do povo japonês, não se aprende pelo que é dito, mas pela imitação do outro; difícil portanto explicar o que não se sabe ao certo o que é, sente-se, percebe-se, mas não se consegue explicitar pelas palavras. Mas também o inverso ocorria, isto é, também dificuldades eram colocadas aos que eram da mesma origem étnica, pois se acreditava que aquele que pertence ao grupo não precisa perguntar, pois tem a obrigação de saber. (Demartini, 1997a; 1997b)

Como se vê, o próprio processo de pesquisa colocou os pesquisadores frente a questões que implicaram no conhecimento do grupo.

\section{MUDANÇAS E PERSISTÊNCIAS ENTRE AS GERAÇÕES: ALGUMAS ANOTAÇÕES}

Considerando o pouco espaço disponível, sintetizamos aqui alguns aspectos observados entre as diferentes gerações com relação a alguns campos, correndo os riscos que estas generalizações nos colocam.

\section{A FAMília EM SUAS DIFERENTES GERAÇÕES}

Entre os imigrantes japoneses a familia tem uma importância muito grande, tendo esta sido reforçada neste período do pós-guerra pelo papel que passou a desempenhar na preservação da cultura japonesa, à medida em que o culto ao Imperador, especialmente nas escolas japonesas, foi perdendo sua importância com a derrota do Japão na $2^{\mathrm{a}}$ Guerra Mundial. Além disso, a família sempre foi cultuada na cultura japonesa, mantendo-se em cada casa o culto aos seus antepassados como prática habitual. Mas o que se percebe é que geralmente são as famílias dos homens (dos chefes e seus descendentes masculinos) as que são mencionadas e às que se atribui maior importância.

No âmbito dos casamentos, hoje não existe mais aquela pressão declarada de casamentos arrumados dentro da colônia como houve para os isseis e nisseis. Antes, a própria cultura japonesa era totalmente oposta ao tipo de casamento livre. Não se admitia amor, isto era uma coisa pecaminosa, o casamento era uma obrigação social. Descartava-se o sentimento, o importante era conservar a família para manter a tradição, o nome e a situação econômica da família. Isso ainda era característico da geração nissei. Mais importante do que o sentimento, era a preservação da tradição. O Miai (que escolhia preliminarmente a família) vem até mais ou me- 
nos os anos 60 e considerava na escolha: a origem da família, a situação econômica, a situação de saúde, etc. Não era apenas uma questão étnica, a estrutura familiar também pesava muito na avaliação. Havia todo um contexto econômico que acompanhava o social. A estrutura da família era o fundamental do Miai. Nas famílias japonesas, com o casamento, as mulheres são praticamente afastadas de suas famílias de origem, incorporando-se às dos cônjuges; desta forma, os relacionamentos se dão predominantemente com os parentes pelo lado do marido. Nota-se que este padrão, neste período considerado, foi se modificando, em virtude até da própria independência que as mulheres descendentes de japoneses passaram a exercitar, na medida em que foram se inserindo profissionalmente no mercado de trabalho urbano, de diferentes maneiras.

Além da própria tradição que preserva os antepassados, os cultua e os coloca como exemplos a serem seguidos, também se observa que, para estas famílias de imigrantes, os que vieram para o Brasil e aqui deram início ao processo de ascensão social e constituíram um novo espaço de vivência para suas famílias são percebidos como "heróis", isto é, como pessoas extremamente importantes na história das famílias observadas, o mesmo sendo verificado entre os jovens. Mesmo quando os jovens da $1^{\mathrm{a}}$ e da $2^{\mathrm{a}}$ imigração ${ }^{3}$ questionam suas famílias, o questionamento é às regras estabelecidas, permanecendo um profundo respeito pelos que as constituíram.

Diferentemente dos jovens da $3^{\text {a }}$ geração, o que se apreende nas representações dos membros das famílias da $1^{\mathrm{a}}$ e $2^{\mathrm{a}}$ gerações de imigrantes japoneses é que à mulher é destinado um lugar extremamente subalterno, sem participação nas decisões e até mesmo na orientação dos filhos a partir de certa faixa etária. Mas, também se verificou que, mesmo nos poucos casos abordados, as mulheres desempenharam papéis de importância fundamental no processo de ascensão da família e até de decisão sobre a orientação profissional dos filhos, o que é reconhecido por eles próprios. Tanto entre os que vivem em situação de colônia, como entre os da $1^{\text {a }}$ e os da $2^{\mathrm{a}}$ imigração, constatou-se que na his- tória destas famílias e de sua sobrevivência no contexto paulistano, algumas mulheres romperam com os papéis a elas atribuídos tradicionalmente nas famílias japonesas. Como também faz parte da cultura japonesa "não se mostrar", este geralmente é um processo silencioso, percebido pelos pesquisadores, mas pouco explicitado por elas próprias; os filhos dão mais indicações nesta direção, ao se manifestarem sobre a influência que as mães tiveram em sua educação e para os destinos da família.

Importante neste processo também são as relações estabelecidas mais intensamente durante o período do pós-guerra destas famílias japonesas com famílias nacionais, com incorporação de novas maneiras de pensar a atuação e o papel da mulher. Os casamentos com pessoas de fora do grupo também parecem exercer uma influência muito grande, pois nem sempre a nora brasileira se submete às regras tradicionais japonesas, em que a mulher tem que sofrer calada as pressões do marido, da sogra, etc. O fato de uma das entrevistadas ter tomado a iniciativa de separar-se do marido (e, portanto, separar-se da família na qual se encontrava inserida), mesmo tendo que arcar com sua sobrevivência e a do filho, é um forte indicador de que neste período mudanças profundas ocorreram no tocante aos papéis familiares.

Nesse aspecto, pode-se pensar que a geração Nissei tenha tido mais conflitos e que a de hoje pode ser uma geração talvez mais tranqüila pois o "campo" está aberto - o cônjuge não é mais necessário ser de ascendência japonesa para se casar. Hoje não há muita responsabilidade com as tradições que vêm da geração anterior. Podemos verificar que aquele sentimento de preservação da família não é tão forte nas novas gerações do Brasil. Segundo a regra dos japoneses, o primogênito - o irmão que iria suceder a família - obrigatoriamente casava em função do arranjo e deveria manter os cuidados dos pais ou então não se casava. Sua compensação estava no recebimento de toda a herança deixada - se houvesse. No Japão, a partir do segundo filho nascia-se livre, mas sem direito algum aos bens familiares. Hoje, pela própria aproximação com a cultura ocidental, juridicamente isso mudou. Aos poucos aquela educação formal da primeira geração voltada para a manutenção de aparências, principalmente na esfera do casamento, já se diluiu. $\mathrm{O}$ processo de mudança tem sido muito acelerado considerando ainda que os casamentos com pessoas de fora do grupo corresponderam a $42 \%$ na $3^{\text {a }}$ geração, atingindo já $62 \%$ na $4^{\mathrm{a}}$ geração ${ }^{4}$.

$\mathrm{O}$ que parece permanecer muito forte das antigas tradições familiares é o respeito aos mais velhos (pais, avós e irmãos), mas não pautado na disciplina rígida e na imposição. A geração dos jovens (sanseis da $1^{\text {a }}$ imigração e nisseis da $2^{\mathrm{a}}$ geração) parece ter vivenciado e se empenhado em uma educação menos rígida, com possibilidade de realizar escolhas: parece haver um espaço e um empenho no diálogo para garantir um respeito mútuo diante das escolhas e influências exercidas por fatores externos à família (certamente este é um processo que tem envolvido conflitos para as gerações que dialogam).

\section{O CAMPO DO TRABALHO}

No caso das famílias japonesas, os relatos de todas as gerações permitem verificar que o trabalho tem um valor muito grande, é a única virtude de sucesso e prosperidade. Assim, se por um lado há uma tradição vinda do Japão com os isseis ( $1^{\text {a }}$ geração), por outro, o fato de terem entrado como imigrantes no país com a tarefa de produzir e trabalhar muito fez com que construíssem a imagem de um povo trabalhador, ideologia que se transferiu aos descendentes. A valorização do trabalho é comum em todas as gerações, variando, entretanto, a forma como é desempenhado e até as dimensões que incorporam ao mesmo. Assim, por exemplo, no tocante às festas, estas deixam de apresentar o caráter de "lazer disfarçado" e assumem a imagem de um "lazer necessário"; isto é, elas são necessárias para a concretização de projetos que atendem à coletividade (o trabalho está sempre presente).

No tocante às atividades desenvolvidas, percebe-se pelas trajetórias das famílias e dos grupos que houve um progressivo processo de ascensão social pautado na inserção diferenciada dos nisseis e sanseis no mercado de trabalho: enquanto muitos chefes de famílias das 1 as gerações 
ainda se dedicavam a atividades agrárias e pensavam na possibilidade de retorno ao Japão, a situação configurou-se de modo diferente para os membros das gerações seguintes. Com a derrota do Japão, desfaz-se qualquer possibilidade de retorno e o investimento prioritário dos pais passa a ser o de preparar os filhos para ocupar uma posição social digna no contexto paulistano, processo que já é observado desde o início da imigração, em São Paulo. O projeto das famílias pauta-se em dar a melhor educação, que pudesse permitir os melhores cargos e profissões, processo que se observa tanto entre famílias de origem rural como entre as mais urbanizadas e que leva a geração dos jovens nisseis e sanseis aos níveis mais elevados de escolaridade do país. Paralelamente, vão se inserindo nos meios empresariais e nas profissões liberais e técnicas, rompendo com a imagem do japonês "agricultor", já entre os da $2^{\text {a }}$ geração, na metrópole. Entre as famílias entrevistadas, o trabalho como dekassegui não se colocou como opção, pois de alguma maneira (com uma exceção) haviam conseguido certa estabilidade econômica e social

\section{O CAMPO DA EDUCAÇÃO}

Em estudo anterior (Demartini, 1997a) mostramos a grande importância que as famílias atribuem à educação e verificamos como as mesmas desenvolveram estratégias para propiciar aos filhos uma educação escolar tanto nos moldes nacionais como em escolas japonesas. Alguns pais, da $1^{\mathrm{a}}$ e $2^{\mathrm{a}}$ gerações, ainda hoje consideram uma "traição" o fato de os filhos não quererem estudar até níveis mais elevados. De fato, as trajetórias individuais e familiares indicam que a escolaridade de níveis mais elevados é procurada e atingida pela maior parte. Mas, também foi possível observar mudanças neste padrão de orientação japonês entre as gerações mais novas. Assim, embora ainda direcionados para profissões "típicas" do grupo japonês (diferenciadas para homens e para mulheres), verifica-se uma constante negação do bom desempenho nos estudos, o que pareceu estar relacionado ao fato de não quererem criar situação de preconceito em relação aos demais brasileiros, que costumam vêlos como ameaça.

No que se refere à questão do apren- dizado da língua japonesa, notou-se que o interesse pela mesma está diretamente relacionado à geração a que pertencem seus pais. Assim, podemos dizer que se para os mais velhos a língua servia como meio de comunicação, união e preservação da cultura japonesa, os jovens entrevistados, em sua maioria, fazem um uso pragmático da mesma, tendo esta perdido seus significados anteriores.

\section{O CAMPO DA SOCIABILIDADE}

$\mathrm{Na}$ esfera da sociabilidade começamos a perceber que existem entre os japoneses algumas divergências quanto às preferências sociais. A geração sansei se afasta da convivência exclusivamente japonesa, estreitando relações com outros brasileiros sem contudo romper totalmente seu contato com os membros do grupo nipônico. Há uma seleção de gostos que ora aproximam e ora afastam essa terceira geração.

O lazer e as práticas esportivas revelam as influências da cultura oriental no país. Entretanto, vale salientar que mesmo tendo perdido seus significados com o tempo, eles representam algo mais profundo do que uma luta marcial ou um arranjo de

As várias gerações no trabalho com terra, na periferia da metrópole paulista (fim dos anos 30 )

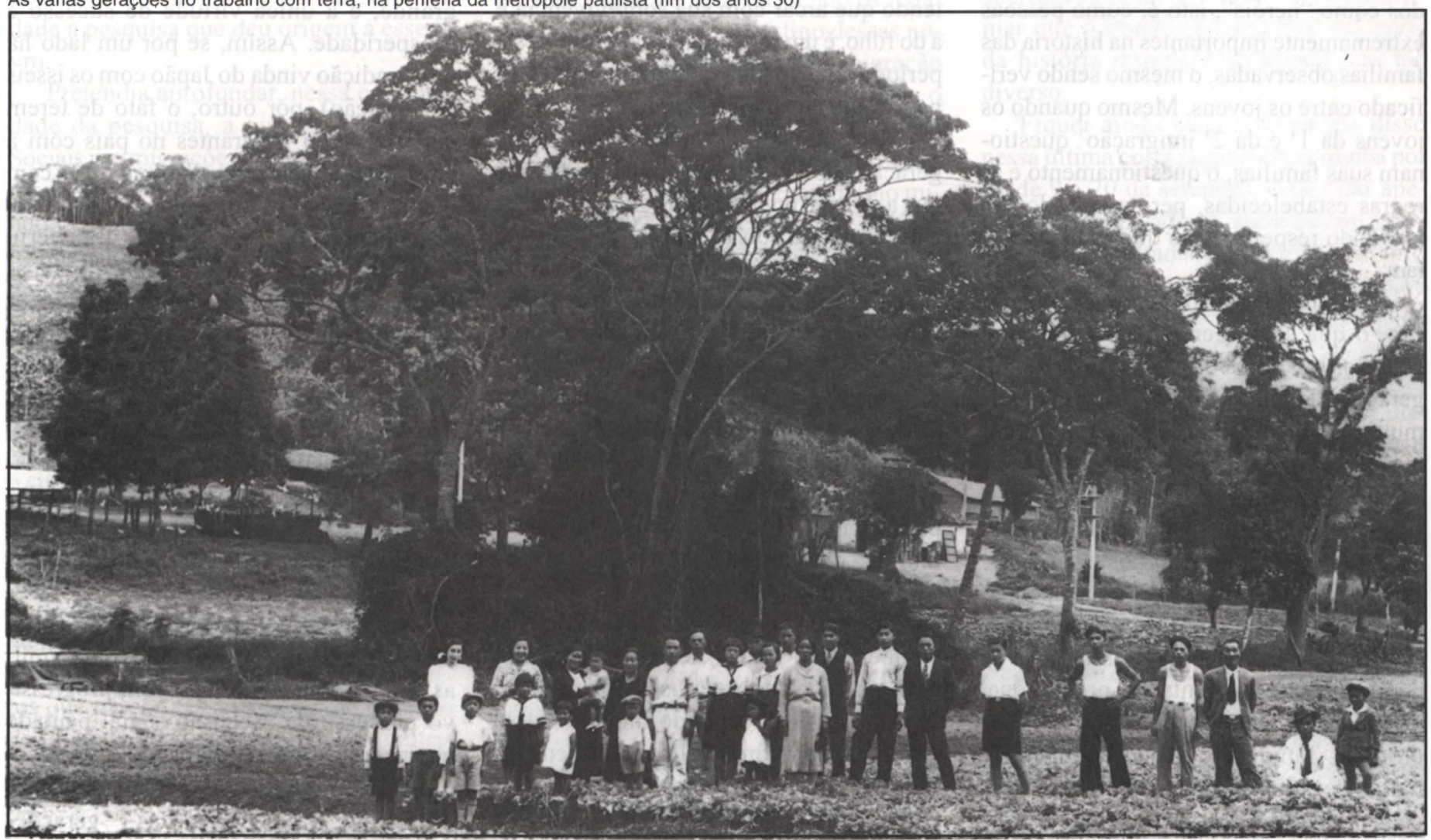

Foto: Reproduzida de álbum de família entrevistada 
flores. Quando se procura dar um sentido filosófico a essas atividades, convém ter em mente que elas movem uma rede de sociabilidade e rituais presentes nos diversos momentos da vida familiar japonesa e criam elos entre pais e filhos, mesmo que eles não tenham continuado as práticas esportivas dos pais. $\mathrm{O}$ fato de ter havido uma "diluição" de certos esportes japoneses no país, indica também uma certa incorporação à sociedade brasileira de costumes diversos, o que tem ocorrido com a comida japonesa, cada vez mais difundida sobretudo nos grandes centros urbanos.

\section{O CAMPO DA SOLIDARIEDADE}

No tocante às famílias japonesas, podese afirmar que o período do pós-guerra implicou, inicialmente, em uma situação de fragilização dos laços de amizade e de convivência com famílias nacionais, na medida em que passaram a ser visualizados como um grupo que trazia intranqüilidade à sociedade paulistana, em virtude dos atentados praticados pela Shindo Renmei ${ }^{5}$. Por outro lado, foi um período de divisão dentro do próprio grupo japonês, na medida em que algumas famílias se posicionaram como "derrotistas" (ou esclarecidas) e outras como "vitoriosas" (Kachi-gumi). Com o passar dos anos, contudo, parece que a tendência foi no sentido de resgatar a união das famílias no seio da "grande colônia" japonesa, que passou a ser chamada de Comunidade Nikkei e também nas várias colônias a elas ligadas, algumas constituídas a partir da vivência em um espaço comum e da participação em atividades culturais e esportivas, como a da Colônia de Itaquera, outras a partir da origem comum no Japão (as várias localidades de origem) ou a partir da vinda no mesmo grupo imigratório, como o que foi analisado entre os imigrantes da $2^{\mathrm{a}}$ imigração (pós 1953). As colônias e suas associações têm presença importante na vida das famílias analisadas, tanto vivendo no mesmo espaço ou espalhadas pela cidade. Como foi possível constatar, a participação em atividades comuns, nos esportes, em festas e excursões promovidas pelas mesmas permite um estreitamento dos laços de solidariedade entre as famílias, possibilidades de apoio nos processos de as- censão social, de estabelecimento de contatos visando casamentos dentro do grupo e também como instituição importante para a preservação de valores culturais japoneses. Mesmo a associação dos jovens universitários, a ABEUNI, mantém os traços das organizações tradicionais. Nesta, entretanto, pode-se perceber que, ao contrário das demais associações que são voltadas em grande parte para os pertencentes à comunidade Nikkei, há um empenho em relacionar-se com as populações nacionais mais pobres através do trabalho assistencial junto às mesmas; mas é também um espaço para a convivência e namoro entre "iguais". O que se pode perceber é que para todas as famílias e grupos a "grande comunidade japonesa" no Brasil é uma presença sentida e um ponto de referência, mesmo quando negada.

Especialmente nas gerações mais jovens há tendências a escapar às pressões e padrões estabelecidos pelo grupo através de suas associações. A geração sansei se afasta da convivência exclusivamente japonesa, estreitando relações com outros brasileiros, sem, contudo, romper totalmente seu contato com os membros do grupo nipônico.

\section{O CAMPO DAS PRÁTICAS RELIGIOSAS}

A pesquisa junto às famílias japonesas, aos grupos de jovens e à colônia evidenciam que muitas famílias não têm uma religião oficial declarada, outras se converteram ao catolicismo já nos primeiros tempos da imigração, outros praticam religiões mais "modernas". Assim, a adesão a uma religião "oficial" não é um traço que caracterize o grupo. Por outro lado, como já foi citado, o importante e presente em todas as famílias é o culto aos ancestrais, prática que é realizada no âmbito de cada família. O culto aos antepassados evidencia a forte importância que a família tem para cada um de seus membros e como, mesmo mortos, os avós e pais continuam presentes no quotidiano familiar, servindo como modelos e como proteção. $\mathrm{O}$ culto aos ancestrais foi reforçado nestas famílias e se manteve, especialmente com a restrição e menor importância atribuída ao culto ao Imperador, após a derrota na guerra.

\section{O CAMPO DA POLÍTICA}

No tocante ao campo da política, observa-se que nas famílias japonesas entrevistadas, tanto vivendo em situações de colônia como espalhadas pela cidade, não parece haver uma preocupação com a projeção nesta área. Este fato foi observado tanto entre as gerações dos isseis, dos nisseis como entre os jovens, que não manifestaram nem interesse por adesão a partidos ou sindicatos políticos.

O que se pode dizer é que ao longo do período considerado, as famílias japonesas de São Paulo procuraram estabelecer laços com os políticos nacionais-locais, de modo a preservar suas realizações ou conseguir melhorias para a colônia ou para a comunidade.

Também se pode afirmar que o exercício da cidadania ocorre entre as várias gerações através da participação em associações, que demandam práticas de cooperação e de votação.

Se há uma aparente "indiferença" atualmente pelas questões políticas, também se pode dizer que foi neste mesmo período por nós considerado que este grupo sofreu as maiores pressões e problemas políticos, em decorrência de fatores diversos e interligados: em primeiro lugar, com a derrota do Japão na $2^{\text {a }}$ Guerra, foram deixando de referir-se ao Estado Japonês e seu nacionalismo, para constituir-se principalmente como "cidadãos" brasileiros; muitos se naturalizaram neste período; em segundo lugar, porque foi neste período que vivenciaram a divisão do próprio grupo em grupos politicamente opostos em virtude do Shindo Renmei, sobre o qual não gostam de falar, período em que foram extremamente discriminados pela população nacional em São Paulo.

Talvez as lembranças e pressões ainda muito recentes tenham relações com a pouca disposição dos indivíduos e das famílias japonesas em participar ativamente de atividades políticas da sociedade mais ampla.

\section{OBSERVAÇÕES FINAIS}

Todas as situações analisadas no estudo com japoneses nos levaram a perceber que no processo de inserção e convivência na sociedade paulistana não há um padrão único, mas uma pluralidade de situa- 
ções que se acentua nas últimas gerações: alguns estão preocupados em manter os valores inerentes à identidade japonesa; alguns tentam negá-los, numa tentativa de se reconhecerem e serem reconhecidos como brasileiros; outros tentam conviver com os valores das duas culturas.

Mas, com uma exceção, todos os entrevistados das gerações mais jovens se consideram "brasileiros", mesmo os que estão empenhados na preservação da cultura japonesa. Para alguns, como vimos acima, eles seriam um "outro" brasileiro, com cara oriental, alguns costumes diferentes, mas brasileiro. Nesta representação de sua identidade "diferenciada' e em transformação profunda, alguns expressam suas dificuldades em conviver e aceitar totalmente o que consideram o jeito de ser "brasileiro"; outros, ao contrário, expressam os conflitos familiares que enfrentam por não seguirem todos os preceitos do estilo de vida oriental praticado em suas famílias; outros, ainda, falam das dificuldades e ressentimentos que enfrentam por não serem reconhecidos como iguais pelos brasileiros. Para todos, as dificuldades em conviver com os traços de uma cultura estruturada secularmente, homogênea em sua percepção, num contexto em rápida transformação e com incorporação de culturas de outros grupos e da cultura brasileira tão "nova" e até indefinida.

Nesta pesquisa procuramos captar a complexidade do real e a diversidade presente no contexto da realidade paulistana (Velho, 1989), o que nos poderia levar a pensar, num primeiro momento, que as ambigüidades e os diferentes processos de construção de identidade fossem fruto desta opção metodológica. Mas também podemos supor que o que está por trás de todas as trajetórias analisadas é a luta pelo pertencimento a uma coletividade, seja ela constituída por pessoas da mesma origem étnica, ou não. O importante, então, não é ter os traços orientais, nem manter o sangue amarelo puro, nem cultuar o Estado Japonês, mas principalmente, preservar o que mais fortemente parece marcar a cultura japonesa de origem: a união entre as pessoas. E, nessa direção, o grupo japonês, que já foi e ainda é em parte considerado o "mais" diferente dos grupos imigrantes, tem recorrido aos valores de sua própria cultura de origem para estabelecer os elos com a população nacional e outros grupos de imigrantes. Talvez por esta razão Hiroshi Saito já questionava em 1978 a possibilidade de existência de uma identidade nipo-brasileira nos moldes da identidade teuto-alemã que se teria constituído entre os alemães isolados do sul: "não acredito na possibilidade da emergência ou perpetuação de um tipo próprio de cultura, digamos, a nipo-brasileira" (Saito, 1980, p. 117).

Estas são questões que permanecem em aberto quando refletimos sobre a diversidade de situações encontradas e as diferentes maneiras como cada pessoa ou cada grupo vai reinventar e reinterpretar suas próprias identidades, no cruzamento da cultura japonesa secular e da cultura brasileira tão "nova" e até indefinida. Mas não resta dúvidas de que, neste processo, em todos os casos, mesmo entre os que tentam negar sua origem japonesa, as estratégias que utilizam para estas reconstruções e para suas vivências no contexto paulistano estão baseadas na cultura de seus antepassados. Os valores da cultura japonesa como união, solidariedade, hierarquia, disciplina, respeito, etc. são eles próprios reinterpretados por cada indivíduo e são a base para o enfrentamento das situações nesta sociedade, o que tem permitido para a maior parte das famílias e das pessoas um estreitamento de relações com a sociedade mais ampla, uma conquista de posições de prestígio e poder nos vários campos sociais e, principalmente, o sentimento de "ser pertencente" a esta sociedade.

*Zeila de Brito F. Demartini é Diretora de Pesquisa e Pesquisadora do CERU-Centro de Estudos Rurais e Urbanos/USP e Prof ${ }^{u}$ da F.E-UNICAMP.

\section{NOTAS}

1. Participaram deste estudo em suas diferentes etapas: Gilmar Santana, Maria Helena Lara Netto, Odila Carvalho Reis, Valéria Magalhães Barbosa, Neide Mayumi Osada, Ellen Cristina Doppenschimitt, Fausto, Lúcia Marina Puga Ferreira e Marisa Pulice Mascarenhas.

2. Segundo o glossário de Tomoo Handa, 1987, essa palavra traduz o encontro arranjado entre moços e moças, por intermediários, chamados de nakôdo (literalmente padrinho ou madrinha de casamento. No Japão, estes também têm a função de intermediar casamentos) para fins matrimoniais.

3. Primeira e Segunda Imigração: pertencem à $1^{\mathrm{a}}$ imigração as familias (diferentes geraçōes) que chega- ram até a Segunda Guerra Mundial e à $2^{\mathrm{a}}$ imigração as familias (diferentes gerações) que aqui chegaram a partir de 1952, no pós-guerra.

4. Dados extraídos da Pesquisa da população de descendentes de japoneses residentes no Brasil - 1987/ 1988. Centro de Estudos Nipo-Brasileiros, São Paulo, 1990.

5. A Shindo Renmei (Liga dos Seguidores do Caminho dos Súditos) foi uma organização fundada em 1944 por ex-militares, que chegou a contar com 110.000 associados, atuando principalmente no Estado de São Paulo. Dedicava-se ao culto ao espirito japonês e à obra de construção da Grande Ásia Oriental.

\section{BIBLIOGRAFIA}

\section{BERTAUX, Daniel.}

(1980) "L'approche biographique: as valideté méthodologique, ses potentialités". Cahiers Internationaux de Sociologie, 59.

CENTRO de Estudos Nipo-Brasileiros

(1980) Pesquisa da população de descendentes de japoneses residentes no Brasil: 1987-1988. São Paulo.

DELCROIX, Catherine

(1995) “Des recits de vie croisés aux histoires des familles". Courrent Sociology, 43(2/3), Autumm/ Winter.

DEMARTINI, Zeila de Brito Fabri

(1992) "Trabalhando com relatos orais: reflexões a partir de uma trajetória de pesquisa". In: LANG, Alice Beatriz (org). Reflexões sobre a pesquisa sociológica. São Paulo, FFLCH/CERU. (Coleção Textos. Série 2, (3):42-60).

DEMARTINI, Zeila de Brito Fabri

(1997a) Viagens vividas, viagens sonhadas: os japoneses em São Paulo na primeira metade deste século. São Paulo, FFLCH/CERU. (Coleção Textos, Série 2, (7)).

DEMARTINI, Zeila de Brito Fabri

(1997b) "Familia, imigração e cultura no pósguerra: os japoneses". São Paulo, CERU. Relatório de Pesquisa, Vol. IV. (digitado)

FERRAROTI, Franco

(1984) "Entretien avec ... Franco Ferraroti". S.I., p. 25-51. (sem título da obra)

GEHRING, U.; GEHRING, P. M. A.

(1991) "Tres geraciones en question". Historia y Fuente Oral, Barcelona, (6).

HANDA, Tomoo

(1987) O imigrante japonês: histórias de sua vida no Brasil. São Paulo, T. A. Queiroz/Centro de Estudos Nipo-Brasileiros.

MAEYAMA, Takashi

(1972) "Ancestor, Emperor, and Immigrant: religion and group identification of the Japanese in rural Brazil (1908-1950)". Journal of Inter-American Studies and Word Affairs, Beverly Hills, 14(2).

SAITO, Hiroshi

(1980) A presença japonesa no Brasil. São Paulo, Edusp.

SIRINELLI, Jean François

(1996) "A geração". In: AMADO, Janaina; FERREIRA, Marieta M. (coords). Usos e abusos da história oral. Rio de Janeiro, FGV.

VELHO, Gilberto

(1989) Subjetividade e sociedade: uma experiência de gerações. $2^{\mathrm{a}}$ ed. Rio de Janeiro, Zahar.

VIEIRA, Francisca I. Schurig

(1973) O japonês na frente de expansão paulista: o processo de absorção do japonês em Marília. São Paulo, Pioneira/Edusp. 